\title{
Response by the calf to stimulus change
}

\author{
K. L. BEAUCHAMP, A. CHAPMAN AND C. GREBING \\ CALIFORNIA STATE POLYTECHNIC COLLEGE, POMONA
}

Calves were given one exposure trial and one choice trial in a $T$ maze. The goal arms differed in brightness on the exposure trial. One arm was changed between trials (so that both were either black or white). Seventeen of 24 Ss chose the changed arm. The results were similar to those previously obtained with rats and support the Dember-Earl theory of stimulus selection.

O'Connell's (1965) review of the theories concerned with the explanation of $\mathbf{T}$ maze alternation generally indicates the superiority (in terms of parsimony and predictive ability) of the "titillation" as opposed to "tedium" theories. Among the tedium theories is Glanzer's original (1953) "stimulus satiation" theory, which states that perceiving one alternative in a two alternative situation builds up stimulus satiation or "boredom" that reduces the probability of reponding to that alternative. Thus, if the goal arms of a $\mathrm{T}$ maze are discriminable, the stimulus satiation theory predicts that the animal will respond on the second trial to the more novel stimulus (goal arm) due to the stimulus satiation produced as a consequence of prior exposure to the other goal arm.

Among the titillation theories is the Dember-Earl theory of stimulus selection (Earl, 1961), which states that temporal changes in stimulation (novelty) of sufficient degree elicit approach behavior. Thus, Dember 8. Earl (1957) suggest that if a sufficient measure of novelty is available, the $\mathrm{S}$ will choose the more novel stimulus (goal arm) not because it is avoiding the less novel, but because it is approaching the more novel stimulus.

Dember (1956) provided an experimental paradigm that partially discriminates between these two theories. Satiated male albino rats were given two trials in a $T$ maze. On Trial 1, the Ss were allowed to explore the stem and choice point for 15 min with the goal arms blocked at the choice point by means of two glass partitions. The Ss could view but not enter the goal arms, one of which was black and the other white. Between the two trials, one of the arms was changed so that they were both the same brightness (black or white) on Trial 2. Also, for Trial 2, the glass partitions were removed so that the $S$ could actually enter a goal arm. On the basis of the stimulus selection theory, it was predicted that the $S$ would enter the changed arm. Since the Ss were assumed to be equally satiated to both black and white arms (through the first exposure), a simple satiation theory does not lead to any prediction of the choice on Trial 2. The data supported the stimulus selection theory-17 of 20 Ss chose the changed arm $(p=.001$, sign test).

The present comparative experiment was designed to examine the generality of the preceeding application of the stimulus selection theory. Dember's (1956) experimental paradigm was utilized with calf rather than rat Ss. Thus, the present experiment provides a test of the same prediction from the stimulus selection theory.

\section{Subjects}

Twenty-four Holstein heifers ranging in age from 5 to 38 days ( $\bar{X}=18$ days) were used. Ss were run between their two normal daily feeding periods (the time since feeding ranged from 1 to $9-1 / 2 \mathrm{~h}, \overline{\mathrm{X}}=4.7 \mathrm{~h}$ ). The experimentally naive Ss were not deprived of water. Apparafus

The Ss were run in their calf barn on two different days. 1 The stem and choice point of the maze consisted of part of the central alley between the calf stalls. The stem was $4 \mathrm{ft}$ wide and $8 \mathrm{ft}$ long. The side and end walls of the stem were covered with brown cardboard so that the Ss could not see into the adjacent stalls. The goal arms consisted of two unused calf stalls, $4 \mathrm{ft}$ wide and $6 \mathrm{ft}$ long. The walls of the goal arms were covered with interchangeable sections of cardboard painted either black or white. The gates leading to each goal arm (stall) were retained. These gates consisted of a set of vertical slats which were spaced wide enough to permit a calf to insert his head inside each stall. The entire floor of the maze was covered with fresh straw on each tost day.

\section{Procedure}

The Ss were randomly assigned to four groups (six Ss each). The groups (consisting of the four possible combinations of brightness and location of change) were: (1) Trial 1-black left, white right and Trial 2black in both arms; (2) Trial 1-white left, black right and Trial 2-black; (3) Trial 1-black left, white right and Trial 2-white; (4) Trial 1-white left, black right and Trial 2-white. The order of testing of Ss was randomized across groups.

The Ss were run by two students (A. C. and C. G.) who were not aware of the theories behind the research until data collection was completed.

On Trial $1 \mathrm{~S}$ was introduced into the stem and allowed to view both goal arms for $20 \mathrm{~min}$. $\mathrm{S}$ was then removed from the maze and the brightness of one goal arm was changed (by replacing the cardboard) and both gates were opened to allow free access to either arm on Trial 2. Immediately following the completion of these operations, $S$ was replaced in the stem and given unlimited time to make a choice (defined as entry of more than half of S's body into either goal arm). The total running time was approximately 30 min per $\mathbf{S}$. 


\section{Results and Discussion}

Five Ss in Group 1, three Ss in Group 2, four Ss in Group 3, and five Ss in Group 4 chose the changed arm. By the sign test, the combined results are significant at the 0.032 level (17 of 24 chose the changed arm).

The difference between the total number of left and right turns (9 and 15, respectively) was within the acceptable range of differences (sign test, $p=0.154$ ) under the assumption that $p$ (left) $=p$ (right). Brightness of the goal arm on the second trial had no significant differential effect on the frequency of response to change (nine choices of changed arm when changed to white, eight choices when black).

These results are consistent with the results of Dember's (1956) original experiment. The significantly large number of choices of the more novel arm cannot be accounted for in terms of simple satiation theory. However, the present data do provide additional support for the Dember-Earl theory of stimulus selection.

It must be noted that Glanzer (1961) has significantly modified his original satiation theory. As noted by $O$ 'Connell (1965) in its modified form the satiation theory is a titillation rather than a tedium theory.
The modified satiation theory, when applied to the present experiment, leads to the same prediction as the stimulus selection theory.

In any case, the present results provide support for the phylogenetic generality of the principle that when an animal is given a choice between two stimuli that are discriminably different in measure of novelty (within acceptable limits of novelty or complexity), the $\mathrm{S}$ will choose the more novel stimulus.

\section{References}

DEMBER, W. N. Response by the rat to environmental change.J. comp. physiol Psychol, 1956, 49, 93-95.

DEMBER, W. N., \& EARL, R. W. Analysis of exploratory, manipulatory, and curiosity behavior. Psychol Rev., 1957, 64, 91-96.

EARL, R. W. A theory of stimulus selection. Hughes Aircraft Special Document, 1961, No. SD61-132.

GLANZER, M. Stimulus satiation: An explanation of spontaneous alternation and related phenomena. Psychol Rev., 1953, 60, 257-268.

GLANZER, M. Changes and interrelations in exploratory behavior. $J$. comp. physiol Psychol, 1961, 54, 433-438.

O'CONNELL, R. H. Trials with tedium and titillation. PsychoL Bull, $1965,63,170-179$.

Note

1. The research was conducted at the Foothill Dairy, Azusa, California. 